\title{
Norval Baitello Júnior \\ Vilém Flusser e a Terceira Catástrofe do Homem \\ ou as Dores do Espaço, a Fotografia e o Vento ${ }^{1}$
}

\section{Encontros e desencontros}

Não pude conhecê-lo pessoalmente em sua imponente e impressionante gestualidade que se fez lenda, uma gestualidade vocal, corporal e de idéias, idéias performáticas. E pode-se dizer que era um brasileiro absolutamente típico. Nascido em Praga, de família judaica, de língua alemã, chegou ao Brasil como muitos imigrantes o fizeram ao longo dos dois últimos séculos. Mas, mais do que ser brasileiro, Vilém Flusser era um "antropófago" da melhor estirpe: devorou a cultura brasileira da mesma maneira como a cultura brasileira devorou as culturas que aqui aportaram. Foi com as ferramentas da "Antropofagia" que Flusser passou a se deliciar com os mais diversos artefatos e fatos da mídia e seus desenvolvimentos. Foi o olhar do antropófago que fez Flusser enxergar muito à frente o cenário futurológico que apenas se descortinava.

Ele deu muitos cursos e palestras no Brasil, também na "minha" universidade, mas não tive a chance de ouvi-lo, não imaginei que aquele pensamento presencial por gestos fosse transformarse em imagem, em ícone, tão próximo e ao mesmo tempo tão distante. Enquanto eu próprio estava na Alemanha para meu "banquete" de doutorado, escrevendo sobre a antropofagia dadaísta e devorando tudo o que o velho continente me oferecia para minha formação, Flusser já tinha devorado o processo de devoração ele mesmo, para devolver à velha Europa a radicalidade visceral perdida ao longo dos mesmos séculos. Mais uma vez estávamos tão próximos e tão distantes.

Estudei em Berlim com dois grandes mestres muito próximos de Flusser, Harry Pross e Ivan Bystrina. Este, exilado da Primavera de Praga, da mesma geração de Flusser, apenas quatro anos mais novo. A mesma Praga que o jovem Vilém deixou aos vinte anos, o também jovem Ivan deixou aos 34. Pelas mãos de Harry Pross, Bystrina é trazido para lecionar na Universidade Livre de Berlim. Pelas mesmas mãos de Pross, Flusser, então já morando na França, veio para sua primeira palestra na Alemanha. Pross organizou, de 1984 a 1993, em sua pequena aldeia, Weiler,

\footnotetext{
1 Artigo publicado no Japão em: Kondo, Kojin/ Suga, Kejiro (Orgs.) How to talk to photography. Tokyo: Kokushokankokai, 2005, p.87 a 94. Em japonês, com tradução de Ryuta Imfuku e Yuka Amano.

2 Refiro-me aqui ao movimento de vanguarda histórica chamado "Antropofagia". Movimento radical, desdobramento do Modernismo brasileiro, teve como um dos principais atores e autores Oswald de Andrade. O Movimento Antropofágico propunha, sob a metáfora da devoração, um procedimento radical de recepção crítica dos fluxos culturais, a contrapelo dos nacionalismos e igualmente a contrapelo dos colonialismos. A metáfora se funda no relatos históricos dos primeiros viajantes europeus no Brasil sobre os indígenas canibais, sobretudo no livro do alemão Hans Staden, A verdadeira história dos selvagens, nus e ferozes devoradores de homens (1548-1555).
} 
nos Alpes alemães, os chamados Internationale Kornhaus Seminare (Seminários Internacionais do Celeiro), reunindo em um antigo celeiro de 200 anos, anualmente por uma semana inteira, as mais polêmicas cabeças para pensar e discutir a comunicação, a mídia, seu entorno e suas projeções. Flusser lá estava, enquanto viveu. Polêmico, surpreendente, com sua gestualidade e oralidade lendárias, surpreendente como um antropófago que digeriu a própria voracidade dos processos da mídia em ebulição. Lá banqueteou e foi banqueteado por Abraham Moles, Lev Kopelev, Vicente Romano, Carlo Mongardini e muitos outros, diante de um pequeno público de 150 pessoas e dos mais importantes jornalistas alemães. Flusser falava como um "profeta da era pós-industrial" (H. Pross) sobre o universo das imagens. E logo polarizava os debates, tendo como notáveis oponentes o dissidente exilado russo Lev Kopelev e o espanhol Vicente Romano. Pross afirma, em suas "Memoiren eines Inländers", que Flusser se apresentava como um mágico, enquanto Kopelev assumia o papel de um "pregador do entendimento". E os seminários transcorriam em clima de prós e contras, com os debates sempre em altíssima temperatura.

Quando em 93, no último Kornhaus-Seminar, fui convidado a participar, Flusser (como também Moles) já não estava vivo. Mas como era um mágico, sua presença dispensava a corporeidade. Suas “imagens" já se espalhavam muito além de Weiler e de São Paulo. Vicente Romano relata uma delas, em célebre polêmica entre ambos. Flusser afirma: "Já não existe nenhuma diferença entre uma maçã e o holograma de uma maçã". Responde então Romano: "Que bom, já não teremos que brigar pela comida, você come o holograma e eu como a maçã!". De tal natureza eram os debates e discussões em Weiler.

Os temas dos 10 seminários: Kitsch; Pátria e Apátridas; Comida em Mudança; Os Amigos e os Outros; Dialeto e Oralidade; Memorar e Jubilar; Euro-Nomadismo; Contos de Fadas mensageiros da liberdade; Jogo e Brinquedo; Tempo e Simultaneidades. Oito deles tiveram a presença de Flusser, com suas inesperadas e radicais intervenções, como um canibal que convence sua vítima a mudar a própria lógica, por puro encantamento de ser devorado. Muitas outras polêmicas nasceram no clima aconchegante do celeiro da pequena Weiler, que iriam marcar o surgimento e o desenvolvimento de uma Teoria da Mídia e de uma Teoria da Imagem ambas polarmente distantes das Teorias da Informação - e Flusser é estrela obrigatória nessas novas constelações.

Do desencontro nasceu o encontro. Pelas mediações de Harry Pross, de Vicente Romano, de Lev Kopelev, de Ivan Bystrina - e não pelo contato direto -, pela imagem e não pelo gesto, pelas idéias e não pelo corpo. Como era um mágico, Flusser continua vivo, aparece se escondendo e desaparece se mostrando. Como uma tecno-imagem, ele consagra a frase de Walter Benjamin: "Esconder significa: deixar rastros. Mas invisíveis. É a arte da mão leve. Rastelli conseguia esconder coisas no ar.” (Benjamin, W. Gesammelte Schriften IV,1:398). 


\section{O Nômade e o Vento}

"Espaço - aqui estão as minhas dores". Com esta frase de Vilém Flusser poderíamos resumir seu pensamento de maneira brutal e definitiva. Mas a frase é ao mesmo tempo um "Aleph borgeano", se desdobra em infinitas e transfinitas possibilidades. Os infinitos são os espaços do nosso entorno e os transfinitos são os (nossos) infinitos interiores. Ambos são insondáveis e enigmáticos: só nos encontramos em seus meandros quando nos perdemos em suas entranhas. Este é o único programa possível para compreender a estratégia da imagem em Flusser: perder-se nos caminhos transfinitos que ele percorre.

A meu ver, constituem portanto suas "Reflexões Nômades" uma chave para a compreensão de sua lógica. Elas foram uma das conferências de Flusser no "Kornhaus". Assim expõe ele. O homem vivenciou três grandes catástrofes ao longo de sua história: a hominização, trazida pelo uso das ferramentas de pedra; a civilização, criada pela vida em aldeias, com sua conseqüente sedentarização; e a terceira catástrofe, em curso e ainda sem nome, é marcada pela volta ao nomadismo, pois as casas se tornaram inabitáveis. Na primeira, o homem desenvolve ferramentas e persegue sua caça, é nômade como a caça e como o vento; ao andar (como o vento), toca e apreende o mundo. $\mathrm{Na}$ segunda, constrói casas, domestica e cria sua caça; começa a possuir coisas e, como possui, torna-se fixo na terra, não mais pode andar para apreender o mundo; cria as imagens tradicionais e a escrita que substituem o mundo e os seus percursos (e somente apreende o mundo com sua mediação). $\mathrm{Na}$ terceira, sua casa fica inabitável, porque por todos os seus buracos entra o vento da informação (com suas imagens técnicas, transmitidas pelas tomadas de eletricidade). Este o conduz a um nomadismo de novo tipo, no qual não é mais o corpo que viaja, navega ou caminha, mas o seu espírito (em latim "spiritus", em grego "pneuma", em hebraico "ruach"), seu vento nômade.

Enquanto o homem gerado pela primeira catástrofe vivia no espaço-tempo do caminhar e de sua caça, uma referência móvel, o da segunda tinha uma referência fixa, sua terra e suas posses. $\mathrm{O}$ homem da terceira catástrofe retorna ao vento, à natureza fluida da informação e dos valores simbólicos. Diz Flusser: "O vento, este intangível fantasmagórico, que impulsiona o nômade a seguir em frente e a cujo chamado este obedece, é uma experiência que para nós se tornou representável como cálculo e computação. Começamos a nos tornar nômades não apenas porque o vento sopra pelas nossas casas perfuradas, mas sobretudo também porque ele penetra em nós." (1997:156).

Pelo espírito do vento, que é o sopro do espírito não visível, chegamos à imaterialidade que caracteriza as tecno-imagens como imagens que fugiram do espaço, como espíritos errantes ou nômades sem corpo. 


\section{As Não-Coisas e as Tecno-Imagens}

A “escalada da abstração" ou "escada da abstração" elaborada por Flusser parte, portanto, da percepção do espaço e das formas de ocupação do mundo. A cada degrau ocorre uma redução, uma perda espacial, a cada passo reduz-se uma das dimensões. "Abstrair significa subtrair", assim começa Flusser seu artigo de 1989, “A caminho das não-coisas”. E assim, subtraindo degrau após degrau, a história da imagem constrói sua "escada da abstração" da maneira que se segue.

Nosso entorno se compunha originalmente de objetos e corpos tridimensionais. Toda mediação com o mundo se processava na tridimensionalidade do gesto e do corpo, da presença e no presente. No momento em que o homem começa a depositar suas marcas sobre objetos e sobre as paredes das cavernas - marcas que se transformam em representações imagéticas desencadeia-se uma revolução de conseqüências imprevisíveis: suas imagens criam um novo olhar e uma nova percepção do tempo, um tempo circular que permite ao observador retornar sempre a um ponto inicial. A circularidade do olhar cria um tempo mágico do eterno retorno. Mas uma das três dimensões do espaço se perde nesta passagem. A dimensão da profundidade (que dá a materialidade palpável, corpórea) perde-se no universo das imagens planas, das tradicionais representações imagéticas sobre superfícies.

O degrau seguinte é alcançado pela transformação das imagens em pictogramas, ideogramas e letras, que abrem ao homem o caminho para o universo da escrita (e de sua decifração, a leitura). As representações planas das imagens transformam-se em representações lineares. $\mathrm{O}$ olhar não mais circula sobre a imagem, mas segue uma linha. E o tempo também não mais permite o eterno retorno. Mais uma dimensão espacial se perde na criação da escrita que dita a linha a ser seguida pelo olhar. Com ela se lineariza o tempo, possibilitando o surgimento do tempo histórico. A linearização do mundo por meio da escrita exigiu a tradução dos mundos tridimensional e bidimensional ao mundo unidimensional. Com a escrita o mundo passa a ser descritível, o que abre os caminhos para o pensamento lógico, linear e conceitual. Abre-se o caminho para a ciência e a técnica: criam-se máquinas que podem dispensar a trabalhosa tarefa de aquisição e distribuição da escrita.

Pois foi justamente este pensamento linear e conceitual que criou as bases para o surgimento dos aparelhos produtores das imagens técnicas ou tecno-imagens. Tais tecno-imagens nada mais têm a ver com as imagens tradicionais, pois são frutos da etapa seguinte na escalada da abstração: não possuem mais nenhuma corporeidade, são uma fórmula, um cálculo, um algoritmo (que apenas se projeta sobre um suporte qualquer: papel, vidro, parede e até mesmo a névoa, o vapor ou o ar). Elas são nulodimensionais, uma vez que a última dimensão espacial que lhes restava 
também é subtraída. As tecno-imagens não são mais uma superfície, mas a construção conceitual de um plano por meio da constelação de grânulos, de pontos de dimensão desprezível, mas que reunidos oferecem a ilusão de uma superfície, um mosaico de pedrinhas. "Cálculo" significava em latim "pedrinha", e "calcular" quer dizer "operar com pedrinhas". As pedrinhas minúsculas se aglutinam no espaço plano, formando a ilusão de imagens.

As tecno-imagens resgatam, assim, a circularidade do olhar, pois trazem de volta a sensação da imagem tradicional, funcionando igualmente de maneira mágica. A escalada da abstração caminha, desse modo, da tridimensionalidade para a bidimensionalidade, desta para a unidimensionalidade e desta outra para a nulodimensionalidade.

Este último universo passa a ocupar cada vez mais as vidas humanas e seu entorno: as coisas (e suas inúmeras versões: os produtos, os objetos, o hardware, a matéria bruta) perdem valor enquanto as não-coisas (e suas igualmente inúmeras manifestações: as marcas, os símbolos, os serviços, o software, o valor agregado, a fama) ganham crescente destaque, importância e valor. A nulodimensão passa a ser o mundo para o qual somos impelidos com crescente veemência. Um mundo no qual somente há espaço para seres fluidos como o vento, evanescentes como a luz, efêmeros como o tempo. O mundo das não-coisas nos desafia, procurando desmaterializar nossas existências, transformando-as em cálculos, grânulos, pontos e números.

\section{Por que justamente a fotografia?}

Vilém Flusser reserva à fotografia um status especial dentre as imagens técnicas: por sua qualidade germinativa da nova era da imagem, pelo resgate da magia após a "desmagicização" promovida pela escrita, pelo retorno à circularidade do olhar, pela volta do tempo do eterno retorno e, sobretudo, por ser ela a inauguração das tecno-imagens, imagens sintéticas compostas por granulação e por cálculos - vale dizer, por ser a fotografia uma imagem que não é imagem. Mas além disso, ele atribui à fotografia a qualidade de ser produto de um aparelho que programa a imagem que capta (e só capta as imagens que programa). Diferentemente das ferramentas, também diferentes das máquinas, os aparelhos têm uma existência complexa. Na relação com suas ferramentas, na era pré-industrial, o homem ocupava o centro. Sempre como sujeito da ação transformadora do mundo, o homem se cercava de ferramentas. Com a chegada das máquinas inverte-se a situação: na era industrial as máquinas passaram a ocupar o centro e o homem é que as cercava, em seu papel de trabalhador. Como o custo das máquinas era sempre muito elevado, quem as possuía detinha também os destinos daqueles que as operavam. Esta era a lógica industrial. Com o advento dos aparelhos, transforma-se a lógica industrial. A máquina fotográfica é apenas a parte menos onerosa do aparelho fotográfico: seu custo é tão baixo que cada fotógrafo 
pode possuir seu próprio equipamento. $\mathrm{O}$ valor está deslocado para o seu programa, previamente dado pelo aparelho. O operador já não está mais ao lado apenas da máquina, tampouco possui uma ferramenta apenas ao seu lado. Ele deve estar dentro do aparelho, fazer parte de seu jogo, perder-se dentro de seu aparelho, buscando suas "potencialidades escondidas". Os aparelhos (e dentre eles também o aparelho fotográfico) devem exceder a capacidade dos seus operadores, pois sua lógica é a do excesso, do inesgotamento de suas possibilidades. É portanto impossível trabalhar (no sentido da era industrial) com o aparelho, pois seu programa já trabalha previamente em lugar do fotografo. Com ele só é possível jogar, brincar com suas possibilidades. Mas ele é um brinquedo complexo, porque seus programas foram produzidos por "metaaparelhos" (a indústria que programa os aparelhos; o parque industrial que programa a indústria; o aparelho econômico-social que programa o parque industrial; o aparelho político-cultural e assim por diante, em uma seqüência sempre aberta para cima).

A fotografia é para Flusser o primeiro objeto pós-industrial, ao qual não se dá valor por sua materialidade (como folheto, como pedaço de papel), mas por sua informação, pelo seu teor semiótico. Ou seja, a coisa não tem valor, somente vale seu lado de não-coisa. E as não-coisas não podem ser possuídas simplesmente. Elas são adquiridas para um período de validade do programa. Assim, transfere-se o poder do detentor do objeto para seu programador. Com isto inverte-se a posse: não é o detentor da foto que a possui, mas a foto que possui seu detentor, sinalizando a "vitória do aparelho sobre o homem". Como num ritual de magia, não é o homem que opera seus símbolos, mas os símbolos que operam o homem. Em relação à fotografia, diz Flusser: "No fundo não somos nós que a manipulamos, é ela quem nos manipula."(1985: 62).

Completa-se aqui o programa da terceira catástrofe, sem nome, aquela que tornou inabitáveis as habitações, empurrando o homem a seguir novamente o seu velho companheiro nômade, o vento, o 'spiritus', o 'pneuma', o 'ruach', em busca do momento germinal do sopro que deu vida ao barro inerte.

\section{Referências}

Flusser, Vilém (1963). Lingua e Realidade. São Paulo: Herder.

Flusser, Vilém (1965). A História do Diabo. São Paulo: Martins.

Flusser, Vilém (1983). Pós-História. São Paulo: Duas Cidades.

Flusser, Vilém (1985). Filosofia da Caixa Preta. São Paulo: Hucitec.

Flusser, Vilém (1987). Die Schrift. Göttingen: Immatrix.

Flusser, Vilém (1993). Dinge und Undinge. München: Carl Hanser.

Flusser, Vilém (1997). Medienkultur. Frankfurt: Fischer.

Flusser, Vilém (1998a). Fiç̧ões Filosóficas. São Paulo: Edusp. 
Flusser, Vilém (1998b). Kommunikologie. Frankfurt: Fischer.

Flusser, Vilém (1998c). Vom Subjekt zum Projekt. Menscbwerdung. Frankfurt: Fischer.

Flusser, Vilém (1999). A Dúvida. Rio de Janeiro: Relume Dumará.

Flusser, Vilém (2002). Filosofia da Caixa Preta. Rio de Janeiro: Relume Dumará.

Kamper, Dietmar (1999). Körper-Abstraktionen. Köln: Vilém Flusser Archiv .

Pross, Harry (1993). Memoiren eines Inländers. München: Artemis.

Pross, Harry, ed. (1985). Kitsch. München: Paul List.

Weischer, Christian, ed.(1993). Dialoge. Zehn Jahre Kornhaus-Seminar. München: Lagrev. 